\title{
Dielectric properties in lead-free piezoelectric (Bi0.5Na0.5)TiO3-BaTiO3 single crystals and ceramics
}

\author{
Authors: C.- S. Chen, C. S. Tu, P.- Y. Chen, Y. Ting, \\ S.- J. Chiu, C. M. Hung, H.- Y. Lee, S.- F. Wang, J. \\ Anthoninappen, V. Hugo Schmidt, and R. R. Chien
}

NOTICE: this is the author's version of a work that was accepted for publication in Journal of Crystal Growth. Changes resulting from the publishing process, such as peer review, editing, corrections, structural formatting, and other quality control mechanisms may not be reflected in this document. Changes may have been made to this work since it was submitted for publication. A definitive version was subsequently published in Journal of Crystal Growth, VOL\# 393, (2014), DOI\# 10.1016/j.jcrysgro.2013.09.011.

C.-S. Chen, C.S. Tu, P.-Y. Chen, Y. Ting, S.-J. Chiu, C.M. Hung, H.-Y. Lee, S.-F. Wang, J. Anthoninappen, V.H. Schmidt, and R.R. Chien, "Dielectric properties in lead-free piezoelectric (Bi0.5Na0.5)TiO3-BaTiO3 single crystals and ceramics," Journal Crystal Growth 393, 129-133 (2014). doi: 10.1016/j.jcrysgro.2013.09.011. 


\title{
Dielectric properties in lead-free piezoelectric $\left(\mathrm{Bi}_{0.5} \mathrm{Na}_{0.5}\right) \mathrm{TiO}_{3}-\mathrm{BaTiO}_{3}$ single crystals and ceramics
}

\author{
C.-S. Chen ${ }^{\text {a }}$, C.S. Tu ${ }^{\text {b, } *}$, P.-Y. Chen ${ }^{\text {c }}$, Y. Ting ${ }^{\mathrm{d}}$, S.-J. Chiu ${ }^{\mathrm{e}}$, C.M. Hung ${ }^{\mathrm{b}}$, H.-Y Lee ${ }^{\mathrm{e}}$, S.-F. Wang ${ }^{\mathrm{d}}$, \\ J. Anthoninappen ${ }^{\mathrm{b}}$, V.H. Schmidt ${ }^{\mathrm{f}}$, R.R. Chien ${ }^{\mathrm{f}}$ \\ a Department of Mechanical Engineering, Hwa-Hsia Institute of Technology, New Taipei City 23567, Taiwan \\ ${ }^{\mathrm{b}}$ Graduate Institute of Applied Science and Engineering, Fu Jen Catholic University, New Taipei City 24205, Taiwan \\ ${ }^{\mathrm{c}}$ Department of Mechanical Engineering, Ming-Chi University of Technology, New Taipei City 24301, Taiwan \\ ${ }^{\mathrm{d}}$ Department of Physics, Fu Jen Catholic University, New Taipei City 24205, Taiwan \\ e National Synchrotron Radiation Research Center, Hsinchu 30076, Taiwan \\ ${ }^{\mathrm{f}}$ Department of Physics, Montana State University, Bozeman, MT 59717, USA
}

\begin{abstract}
A B S T R A C T
The $0.93\left(\mathrm{Bi}_{0.5} \mathrm{Na}_{0.5}\right) \mathrm{TiO}_{3}-0.07 \mathrm{BaTiO}_{3}(\mathrm{BNB7T})$ piezoelectric single crystals and ceramics have been grown respectively by using the self-flux and solid-state-reaction methods. The real $\left(\varepsilon^{\prime}\right)$ and imaginary $\left(\varepsilon^{\prime \prime}\right)$ parts of the dielectric permittivity of BNB7T crystals and ceramics were investigated with and without an electric $(E)$ poling as functions of temperature and frequency. The BNB7T crystal shows a stronger dielectric maximum at $T_{m} \sim 240{ }^{\circ} \mathrm{C}$ than the ceramic at $T_{m} \sim 300{ }^{\circ} \mathrm{C}$. The dielectric permittivity of BNB7T ceramic shows an extra peak after poling at an electric field $E=40 \mathrm{kV} / \mathrm{cm}$ in the region of $80-100{ }^{\circ} \mathrm{C}$ designated as the depolarization temperature $\left(T_{d}\right)$. A wide-range dielectric thermal hysteresis was observed in BNB7T crystal and ceramic, suggesting a first-order-like phase transition. The dielectric permittivity $\varepsilon^{\prime}$ obeys the Curie-Weiss equation, $\varepsilon^{\prime}=C /\left(T-T_{o}\right)$, above $500{ }^{\circ} \mathrm{C}$, which is considered as the Burns temperature $\left(T_{B}\right)$, below which polar nanoregions begin to develop and attenuate dielectric responses.
\end{abstract}

\section{Introduction}

Lead-free ferroelectric(FE)/piezoelectric polycrystalline ceramics have been developed in recent years because of environmental concern and global regulations. The $\left(\mathrm{Bi}_{0.5} \mathrm{Na}_{0.5}\right) \mathrm{TiO}_{3}$ (BNT)-based solid solutions substituted with various ions in the A or B sites of the perovskite unit cell have been extensively studied, such as BNT$\mathrm{BaTiO}_{3}$ [1], BNT- $\left(\mathrm{Bi}_{0.5} \mathrm{~K}_{0.5}\right) \mathrm{TiO}_{3}$ [2-4], BNT-KNbO${ }_{3}$ [5], BNT-BiFeO [6], BNT-SrTiO 3 [7], and BNT-BaTiO ${ }_{3}-\left(\mathrm{K}_{0.5} \mathrm{Na}_{0.5}\right) \mathrm{NbO}_{3}$ [8]. The BNT ceramic shows a large coercive field $\left(E_{c}=73 \mathrm{kV} / \mathrm{cm}\right)$ and remanent polarization $\left(P_{r}=38 \mu \mathrm{C} / \mathrm{cm}^{2}\right)$ at room temperature [9]. The ferroelectric BNT relaxor has a high Curie temperature of $T_{c}=320^{\circ} \mathrm{C}$ [9-12].

Among lead-free piezoelectric materials, $(1-x)\left(\mathrm{Bi}_{0.5} \mathrm{Na}_{0.5}\right)$ $\mathrm{TiO}_{3}-x \mathrm{BaTiO}_{3}$ (abbreviated as BNB100xT) solid solutions reported firstly by Takenaka et al. [11] have been of particular interest because of the existence of a morphotropic phase boundary (MPB) near $x=0.06-0.07$, whose piezoelectric properties appear similar to those of the $\mathrm{Pb}\left(\mathrm{Zr}_{1-\chi} \mathrm{Ti}_{x}\right) \mathrm{O}_{3}$ (PZT) piezoelectric ceramics.
The $(1-x)\left(\mathrm{Bi}_{0.5} \mathrm{Na}_{0.5}\right) \mathrm{TiO}_{3}-(x) \mathrm{BaTiO}_{3}$ compositions for $x=0-0.15$ undergo a FE-to-antiferroelectric (AFE) phase transition above a temperature commonly denoted as depolarization temperature $\left(T_{d}\right)[13,14]$. Compared with pure BNT, the BNB7T has shown a smaller coercive field and stronger piezoelectric responses [1-15].

Most studies of $(1-x)\left(\mathrm{Bi}_{0.5} \mathrm{Na}_{0.5}\right) \mathrm{TiO}_{3}-x \mathrm{BaTiO}_{3}$ materials were focused on the ceramics since it is difficult to grow large-size and high-quality BNB100xT single crystals due to the high volatility of the bismuth and sodium components at melting temperatures. However, piezoelectric properties of BNB100xT have not yet been improved significantly due to several factors, such as grain size, microstructures, crystallographic orientation, compositional homogeneity, and internal defects [16-22]. It is commonly accepted that single crystals often provide better piezoelectric properties and less defects than polycrystalline ceramics. The anisotropic characteristics of single crystals are also expected to be used in optical applications, such as optical sensors and actuators.

Since the MPB of $(1-x)\left(\mathrm{Bi}_{0.5} \mathrm{Na}_{0.5}\right) \mathrm{TiO}_{3}-(x) \mathrm{BaTiO}_{3}$ compositions occurs near $x=0.07$, structures, dielectric properties, and phase transformations of $0.93\left(\mathrm{Bi}_{0.5} \mathrm{Na}_{0.5}\right) \mathrm{TiO}_{3}-0.07 \mathrm{BaTiO}_{3}$ (BNB7T) crystals and ceramics have been compared in this work. The E-field poling effects were also explored in dielectric permittivity. The fits of Curie-Weiss equation suggest that the polar nanoregions 
(or nanoclusters) begin to develop below the Burns temperature at $T_{B} \sim 500{ }^{\circ} \mathrm{C}$ in BNB7T crystal and ceramic, and cause the broad frequency-dependent dielectric responses.

\section{Experiments}

The BNB7T single crystals were grown using the high temperature self-flux method. High-purity (>99.9\%) $\mathrm{Bi}_{2} \mathrm{O}_{3}, \mathrm{Na}_{2} \mathrm{CO}_{3}$, $\mathrm{BaCO}_{3}$, and $\mathrm{TiO}_{2}$ powders were used as starting materials, with $\mathrm{Bi}_{2} \mathrm{O}_{3}$ and $\mathrm{Na}_{2} \mathrm{CO}_{3}$ as self-flux materials. According to the compositional formula of $\left(\mathrm{Bi}_{0.5} \mathrm{Na}_{0.5}\right)_{0.93} \mathrm{Ba}_{0.07} \mathrm{TiO}_{3}$, stoichiometric amounts of powders were weighed and mixed in ethanol and milled with zirconia balls for more than $24 \mathrm{~h}$. The mixed powders were then calcined at $900 \mathrm{C}$ in an alumina crucible for $2 \mathrm{~h}$, which yielded single-phase powders. The calcined BNB7T powders mixed with excess $\mathrm{Bi}_{2} \mathrm{O}_{3}$ and $\mathrm{Na}_{2} \mathrm{CO}_{3}$ flux were soaked at $1300{ }^{\circ} \mathrm{C}$ for $1 \mathrm{~h}$ in a platinum crucible and then cooled to $1050{ }^{\circ} \mathrm{C}$ in the ambient environment of the tube furnace. The BNB7T crystals grown with a cooling rate of $1^{\circ} \mathrm{C} / \mathrm{h}$ have larger sizes and show a light-yellow color with maximum dimensions of $8 \times 8 \times 5 \mathrm{~mm}^{3}$ as shown in Fig. 1(a). However, the BNB7T crystals grown with a faster cooling rate of $5{ }^{\circ} \mathrm{C} / \mathrm{h}$ exhibit smaller sizes with a bluish color.

Polycrystalline BNB7T ceramics were synthesized using the solid-state-reaction method. Stoichiometric amounts of $\mathrm{Bi}_{2} \mathrm{O}_{3}$, $\mathrm{Na}_{2} \mathrm{CO}_{3}, \mathrm{BaCO}_{3}$, and $\mathrm{TiO}_{2}$ powders were used as starting materials and were mixed in ethanol with zirconia balls for about $24 \mathrm{~h}$. The
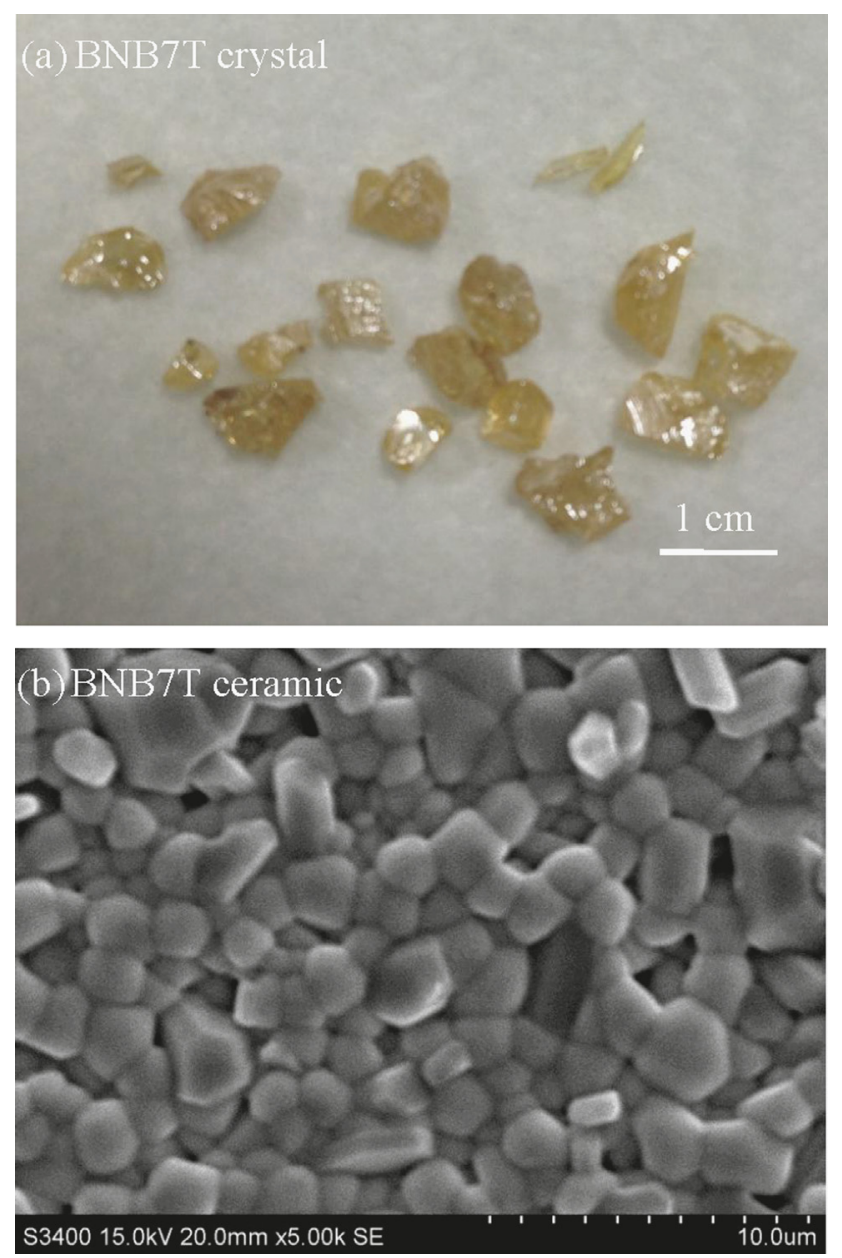

Fig. 1. (a) As-grown BNB7T crystal and (b) SEM grain morphology of sintered BNB7T ceramic at room temperature. (For interpretation of the references to color in this figure legend, the reader is referred to the web version of this article.) mixture was calcined at $900{ }^{\circ} \mathrm{C}$ for $2 \mathrm{~h}$ and a high-energy ball milling method using a Retsch PM100 planetary mill was employed to reduce particle size. The powder mixture was pressed into a $1.0 \mathrm{~cm}$-diameter disk for sintering at $1150{ }^{\circ} \mathrm{C}$ for $1 \mathrm{~h}$. The SEM photograph of Fig. 1(b) shows the morphology of sintered BNB7T ceramic with grain sizes of $1-3 \mu \mathrm{m}$.

Structures of unit cells were determined by using a conventional Rigaku Multiplex X-ray Diffractometer and high-resolution synchrotron XRD performed at the National Synchrotron Radiation Research Center (in Taiwan) with photon energy of $8.0 \mathrm{keV}$ $(\lambda=1.5498 \AA$ ) $)$. The high-resolution synchrotron XRD peaks were fitted with Gaussian profiles. Two processes were used in the dielectric measurements with a Wayne-Kerr Analyzer PMA3260A. In the first process, the dielectric permittivity was taken upon heating and cooling without a prior dc E-field poling. In the second process, the sample was poled at room temperature with a dc $E$ field of $40 \mathrm{kV} / \mathrm{cm}$, then dielectric permittivity was measured without a dc $E$ field. The coercive field $\left(E_{c}\right)$ of BNB7T ceramic is about $30 \mathrm{kV} / \mathrm{cm}$ as shown in Fig. 2. The dielectric loss is defined as $\tan \delta=\varepsilon^{\prime \prime} \mid \varepsilon^{\prime}$.

\section{Results and discussion}

Fig. 3(a) shows the conventional XRD of the as-grown BNB7T crystal at room temperature, indicating a $\left(\begin{array}{lll}0 & 0 & 1\end{array}\right)$ crystallographic orientation. The $2 \theta$ diffraction position and $d$ spacing obey the Bragg law $2 d_{(h k l)} \sin \theta_{(h k l)}=n \lambda$, where $(h k l)$ is the crystallographic orientation. For a tetragonal unit cell, two $d$ spacings are expected from the $(200)$ or $(002)$ reflections according to the

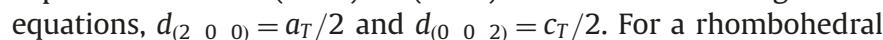
unit cell, one $d$ spacing is expected from the $\left(\begin{array}{lll}0 & 0 & 2\end{array}\right)$ reflection, i.e. $d_{\left(\begin{array}{lll}0 & 0 & 2\end{array}\right)}=a_{R}\left(1-3 \cos ^{2} \alpha+2 \cos ^{3} \alpha\right)^{1 / 2} /\left(4 \sin ^{2} \alpha\right)^{1 / 2}$.

The high-resolution $\left(\begin{array}{lll}0 & 0 & 2\end{array}\right)$ synchrotron XRD of BNB7T crystal as shown in Fig. 3(b), reveals one rhombohedral $(R)$ and two tetragonal ( $T$ ) peaks, indicating coexisting phases of $R$ and $T$ structures. In addition to $R$ and $T$ reflections, an extra broad peak appears at lower $2 \theta$, possibly indicating a coherent superimposition of diffracted waves from nanostructures. Nanostructures are often expected in relaxor FE crystals to accommodate the lattice distortion $[23,24]$. From the fitting parameters, the lattice constants of the tetragonal unit cell are calculated to be $c_{T}=3.956 \AA$ and $a_{T}=3.893 \AA$ at room temperature. The XRD of sintered BNB7T ceramic is given in Fig. 3(c) and shows no splitting, suggesting a pseudocubic unit cell.

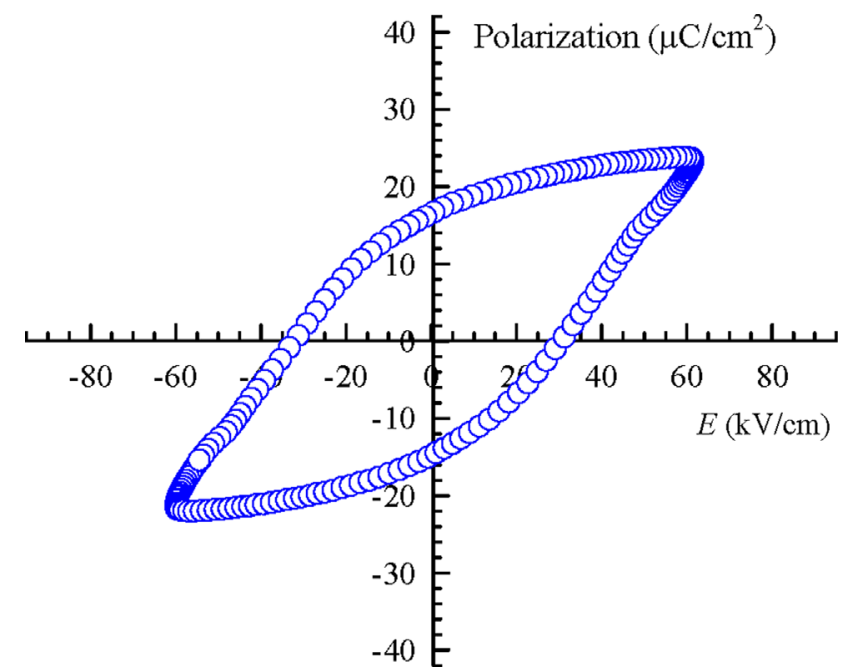

Fig. 2. Hysteresis loop of electric polarization versus $E$ field of BNB7T ceramic. 
a
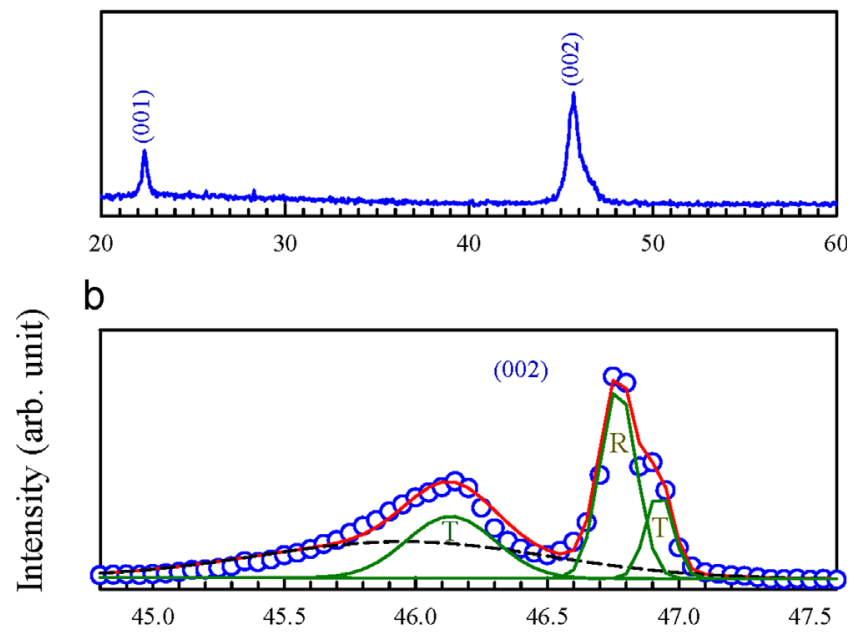

C

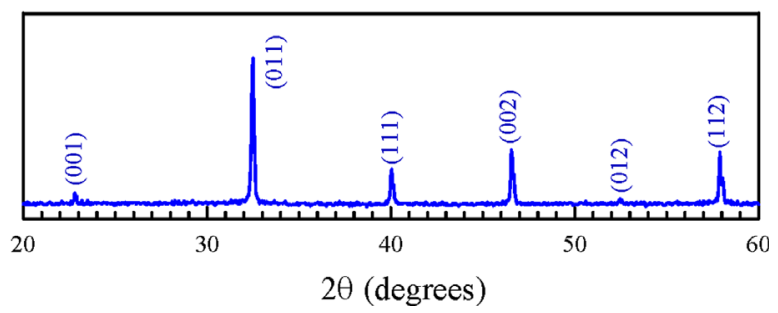

Fig. 3. (a) Conventional XRD of as-grown BNB7T crystal. (b) High-resolution $\left(\begin{array}{lll}0 & 0 & 2\end{array}\right)$ synchrotron XRD. The green lines are fits of two tetragonal $(T)$ and one rhombohedral $(R)$ peaks. The dashed broad peak indicates a coherent superimposition of diffracted waves from nanostructures. The red line is sum of fitting curves. (c) XRD of sintered BNB7T ceramic. (For interpretation of the references to color in this figure legend, the reader is referred to the web version of this article.)

The dielectric permittivity and loss of ( $\left.\begin{array}{lll}0 & 0 & 1\end{array}\right)$-cut BNB7T crystal (Fig. 4), show similar dielectric responses before and after poling at $E=40 \mathrm{kV} / \mathrm{cm}$. This implies that the prior $E$-field poling did not affect the polarization ordering in the $\left(\begin{array}{lll}0 & 0 & 1\end{array}\right)$-cut BNB7T crystal. The room-temperature $\varepsilon^{\prime}$ of unpoled BNB7T crystal for $f=1 \mathrm{MHz}$ is about 1200, which is larger than $\varepsilon^{\prime} \sim 620$ in pure BNT crystal [25]. The dielectric maximum appears at $T_{m} \sim 240{ }^{\circ} \mathrm{C}$ and is $\varepsilon^{\prime}$ max $\sim 4400$. The dielectric permittivity $\varepsilon^{\prime}$ below $T_{m} \sim 240{ }^{\circ} \mathrm{C}$ exhibits an extensive frequency dispersion with a shoulder near $160{ }^{\circ} \mathrm{C}$. The dielectric permittivity $\varepsilon^{\prime}$ above $500{ }^{\circ} \mathrm{C}$ obeys the Curie-Weiss equation, $\varepsilon^{\prime}=C /\left(T-T_{\mathrm{o}}\right)$, as indicated by the dashed lines with the constants of $C=2.4 \times 10^{5}{ }^{\circ} \mathrm{C}$ and $T_{o}=340{ }^{\circ} \mathrm{C}$ for the unpoled crystal, and $C=2.6 \times 10^{5}{ }^{\circ} \mathrm{C}$ and $T_{o}=340{ }^{\circ} \mathrm{C}$ for the poled crystal. The temperature of $500{ }^{\circ} \mathrm{C}$ is considered to be the Burns temperature $\left(T_{B}\right)$, below which the polar nanoregions (or nanoclusters) begin to develop and attenuate dielectric responses under ac measuring $E$ field. The dynamics of polar nanoregions is responsible for the broad dielectric dispersion [26].

The room-temperature dielectric losses of BNB7T crystal for $f=1 \mathrm{MHz}$ before and after poling are about 0.09 , which is slightly larger than 0.05 in pure BNT crystal [25]. The dielectric loss exhibits a strong frequency dispersion and broad maximum in the region of $100-160{ }^{\circ} \mathrm{C}$. This diffuse phenomenon suggests a relaxor FE feature and a progressive transition from the FE state to relaxor state at lower temperature region. A phase-shifted conductivity is evident at higher temperatures $\left(>500{ }^{\circ} \mathrm{C}\right)$, above which the dielectric loss is larger than 1 and rises exponentially with increasing temperature. The phase-shifted conductivity is mainly due to the thermally activated ionic conduction [27].

The dielectric permittivity and loss of BNB7T ceramic are given in Fig. 5 and exhibit very different dielectric responses before and
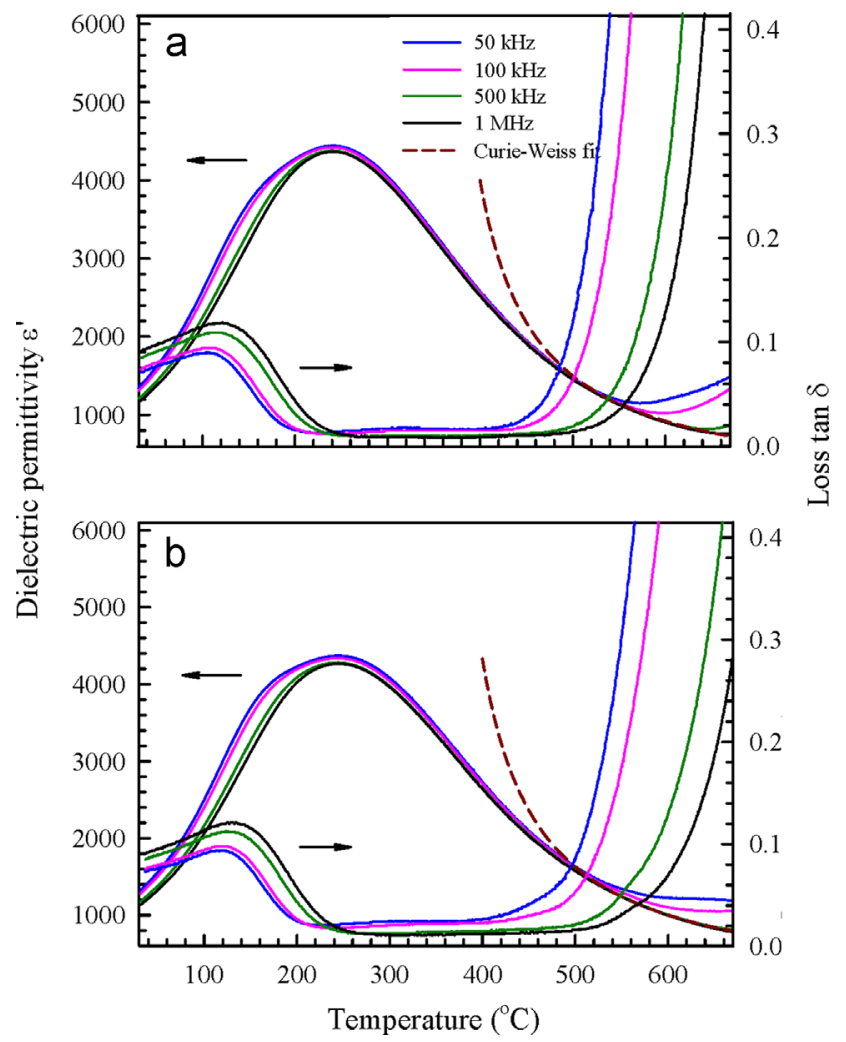

Fig. 4. Dielectric permittivity $\varepsilon^{\prime}$ and loss of BNB7T crystal before and after poling at $E=40 \mathrm{kV} / \mathrm{cm}$. The dashed lines are the fits of Curie-Weiss equation.

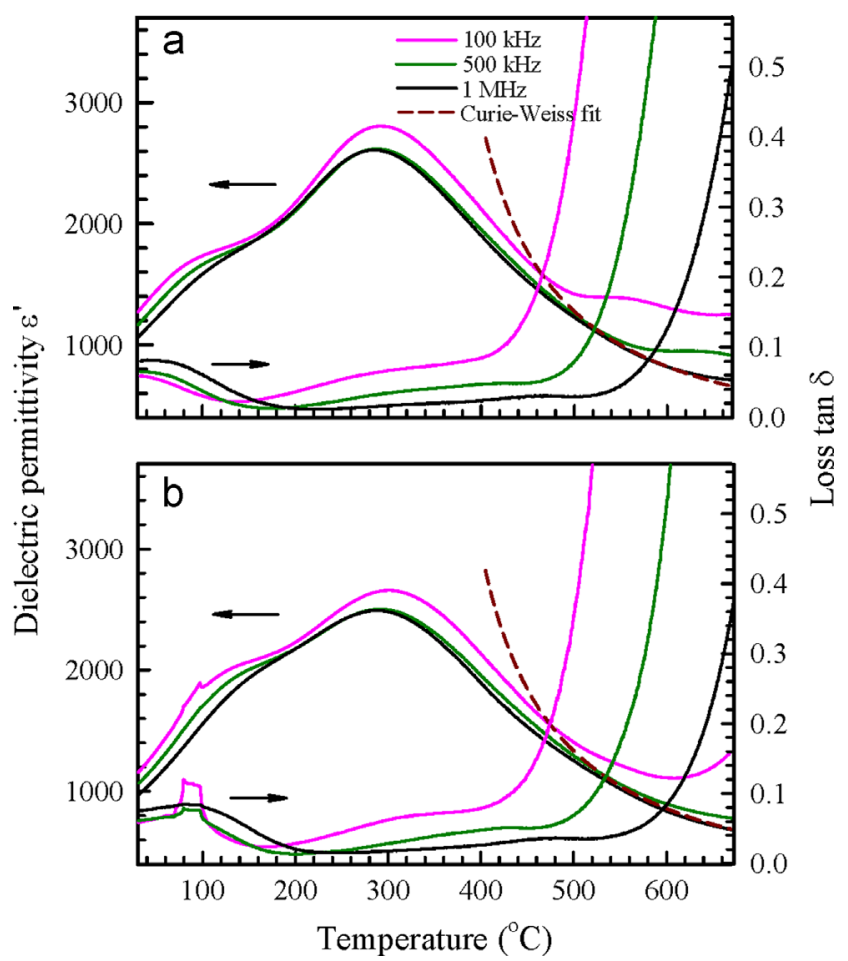

Fig. 5. Dielectric permittivity $\varepsilon^{\prime}$ and loss of BNB7T ceramic before and after poling at $E=40 \mathrm{kV} / \mathrm{cm}$.

after poling at $E=40 \mathrm{kV} / \mathrm{cm}$. The dielectric permittivity of BNB7T ceramic shows an extra peak after poling at $E=40 \mathrm{kV} / \mathrm{cm}$ in the region of $80-100{ }^{\circ} \mathrm{C}$, which is designated as the depolarization temperature $\left(T_{d}\right)$. These phenomena suggest that the prior $E$-field poling affects the low-temperature polarization ordering in BNB7T 


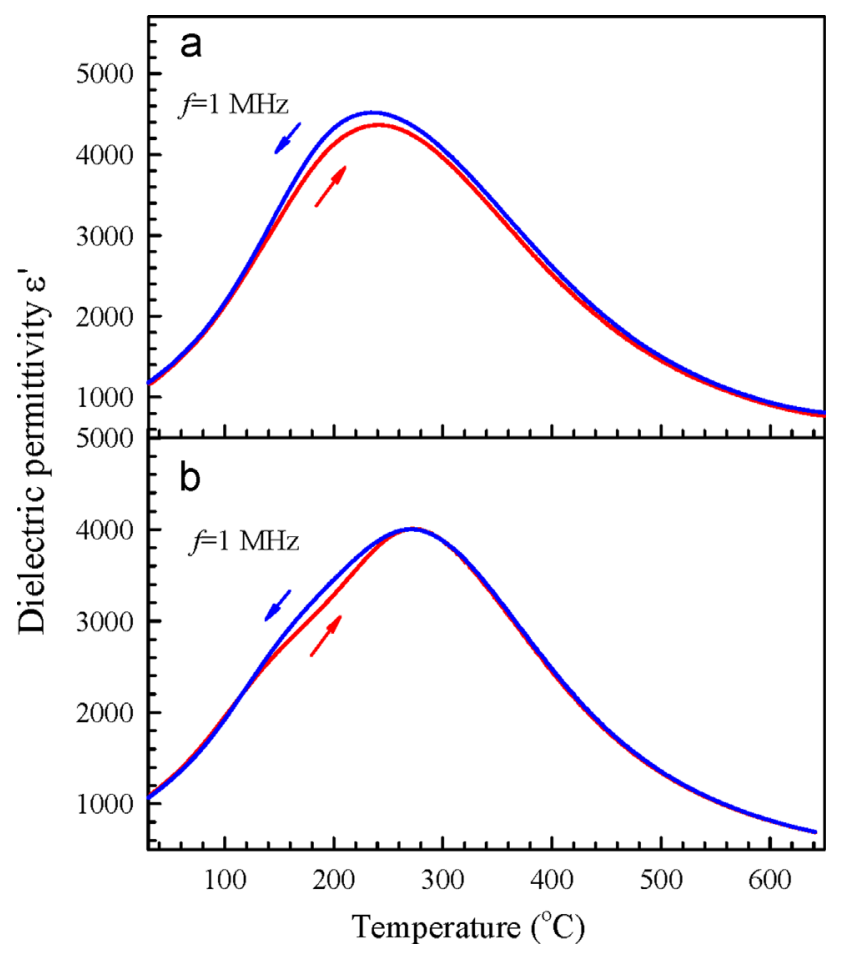

Fig. 6. Dielectric thermal hystereses of unpoled BNB7T crystal and ceramic at $f=1 \mathrm{MHz}$.

ceramic. The room-temperature $\varepsilon^{\prime}$ for $f=1 \mathrm{MHz}$ is about 1060 and 980 before and after poling, respectively. This slight decrease in $\varepsilon^{\prime}$ is likely due to the reduction of polarization disordering after poling along the measuring $E$-field direction. The dielectric maxima $\varepsilon_{\text {max }}^{\prime}$ of BNB7T ceramic appear at $T_{m} \sim 300{ }^{\circ} \mathrm{C}$ and are about 2800 and 2600 before and after poling. The dielectric permittivity $\varepsilon^{\prime}$ below $160{ }^{\circ} \mathrm{C}$ exhibits an extensive frequency dispersion. The dielectric permittivity $\varepsilon^{\prime}$ above $500{ }^{\circ} \mathrm{C}$ follows the Curie-Weiss equation as described by dashed lines with $C=2.3 \times 10^{5}{ }^{\circ} \mathrm{C}$ and $T_{o}=320{ }^{\circ} \mathrm{C}$ for the unpoled ceramic, and $C=2.4 \times 10^{5}{ }^{\circ} \mathrm{C}$ and $T_{o}=320^{\circ} \mathrm{C}$ for the poled ceramic.

The room-temperature dielectric losses of BNB7T ceramic for $f=1 \mathrm{MHz}$ before and after poling have a similar value of 0.08 . The dielectric loss of BNB7T ceramic after poling at $E=40 \mathrm{kV} / \mathrm{cm}$ shows an extra peak in the region of $80-100{ }^{\circ} \mathrm{C}$, suggesting a transformation from ordered to disordered states upon heating. The dielectric loss begins to increase exponentially for temperatures higher than $500{ }^{\circ} \mathrm{C}$, implying that the high-temperature dielectric responses are associated with the phase-shifted conductivity [27].

BNB7T crystal and ceramic exhibit a wide-range dielectric thermal hysteresis in Fig. 6, suggesting a first-order like phase transition. The thermal hysteresis of BNB7T crystal begins below $500{ }^{\circ} \mathrm{C}$ and ends at $-120^{\circ} \mathrm{C}$ in Fig. 6(a). Based on Fig. 3(b) which shows an $R+T$ coexistence in our crystal at room temperature, and an $R-R+T-T-C$ transition sequence observed in a pure (l0 011$)$ cut BNT crystal [25], we propose that the thermal hysteresis suggests a sequence of $R+T-T-C$ (cubic) phase transitions upon heating. In BNB7T ceramic, the thermal hysteresis occurs in the region of $130-250{ }^{\circ} \mathrm{C}$. This broad thermal hysteresis likely corresponds to a gradual first-order structural transition from a coexisting $R+T$ to $T$ phases.

\section{Conclusions}

The dielectric permittivity and loss of BNB7T piezoelectric crystals and ceramics with and without a prior E-field poling, have been investigated as functions of temperature and measuring frequency. The (0 001 )-cut BNB7T crystal shows stronger dielectric responses than the BNB7T ceramic. The dielectric permittivity and loss of poled BNB7T ceramic show a depolarization peak at 80-100 ${ }^{\circ} \mathrm{C}$. However, the depolarization peak was not observed in the poled BNB7T crystal, indicating that the external $E$ field did not largely change the ordered state noticeably in the poled crystal. A wide-range dielectric thermal hysteresis was observed in BNB7T crystal and ceramic, suggesting a first-order-like phase transition. The dielectric permittivity $\varepsilon^{\prime}$ obeys the Curie-Weiss equation above $500{ }^{\circ} \mathrm{C}$, which is considered as the Burns temperature $\left(T_{B}\right)$, below which polar nanoregions (or nanoclusters) begin to develop.

\section{Acknowledgement}

This project is supported by National Science of Council of Taiwan under grant numbers 102-2221-E-146-001, 102-2221-E131-006, and 100-2112-M-030-002-MY3.

\section{References}

[1] S.T. Zhang, A.B. Kounga, E. Aulbach, Y. Deng, Temperature-dependent electrica properties of $0.94 \mathrm{Bi}_{0.5} \mathrm{Na}_{0.5} \mathrm{TiO}_{3}-0.06 \mathrm{BaTiO}_{3}$ ceramics, Journal of the American Ceramic Society 91 (12) (2008) 3950.

[2] K. Yoshii, Y. Hiruma, H. Nagata, T. Takenaka, Electrical properties and depolarization temperature of $\left(\mathrm{Bi}_{1 / 2} \mathrm{Na}_{1 / 2}\right) \mathrm{TiO}_{3}-\left(\mathrm{Bi}_{1 / 2} \mathrm{~K}_{1 / 2}\right) \mathrm{TiO}_{3}$ lead-free piezoelectric ceramics, Japanese Journal of Applied Physics 45 (5B) (2006) 4493.

[3] A. Sasaki, T. Chiba, Y. Mamiya, E. Otsuki, Dielectric and piezoelectric properties of $\left(\mathrm{Bi}_{0.5} \mathrm{Na}_{0.5}\right) \mathrm{TiO}_{3}-\left(\mathrm{Bi}_{0.5} \mathrm{~K}_{0.5}\right) \mathrm{TiO}_{3}$ systems, Japanese Journal of Applied Physics 38 (1999) 5564

[4] P.Y. Chen, C.C. Chou, T.Y. Tseng, H. Chen, Second phase and defect formation in $\mathrm{Bi}_{0.5} \mathrm{Na}_{0.5-\mathrm{x}} \mathrm{K}_{\mathrm{x}} \mathrm{TiO}_{3}$ ceramics, Japanese Journal of Applied Physics 49 (2010) 061506.

[5] Y. Hiruma, H. Nagata, T. Takenaka, Phase diagrams and electrical properties of $\left(\mathrm{Bi}_{1 / 2} \mathrm{Na}_{1 / 2}\right) \mathrm{TiO}_{3}$-based solid solutions, Journal of Applied Physics 104 (2008) 124106.

[6] H. Nagata, N. Koizumi, T. Takenaka, Lead-free piezoelectric ceramics of $\left(\mathrm{Bi}_{1 / 2} \mathrm{Na}_{1 / 2}\right) \mathrm{TiO}_{3}-\mathrm{BiFeO}_{3}$ system, Key Engineering Materials 169 (1999) 37.

[7] Y. Hiruma, Y. Imai, Y. Watanabe, T. Takenaka, Large electrostrain near the phase transition temperature of $\left(\mathrm{Bi}_{0.5} \mathrm{Na}_{0.5}\right) \mathrm{TiO}_{3}-\mathrm{SrTiO}_{3}$ ferroelectric ceramics, Applied Physics Letters 92 (2008) 262904.

[8] S.T. Zhang, A.B. Kounga, E. Aulbach, J. Rodel, Giant strain in lead-free piezoceramics $\mathrm{Bi}_{0.5} \mathrm{Na}_{0.5} \mathrm{TiO}_{3}-\mathrm{BaTiO}_{3}-\mathrm{K}_{0.5} \mathrm{Na}_{0.5} \mathrm{NbO}_{3}$ system, Applied Physics Letters 91 (2007) 112906

[9] G.A. Smolenskii, V.A. Isupov, A.I. Agranovskaya, N.N. Krainik, New ferroelectrics of complex composition IV, Soviet Physics, Solid State 2 (1961) 2651

[10] C.F. Buhrer, Some properties of bismuth perovskites, Journal of Chemical Physics 36 (1962) 798.

[11] T. Takenaka, K. Maruyama, K. Sakata, $\left(\mathrm{Bi}_{1 / 2} \mathrm{Na}_{1 / 2}\right) \mathrm{TiO}_{3}-\mathrm{BaTiO}_{3}$ system for leadfree piezoelectric ceramics, Japanese Journal of Applied Physics 30 (1991) 2236.

[12] C. Tu, I. Siny, V. Schmidt, Sequence of dielectric anomalies and hightemperature relaxation behavior in $\mathrm{Na}_{1 / 2} \mathrm{Bi}_{1 / 2} \mathrm{TiO}_{3}$, Physical Review B: Condensed Matter 49 (1994) 11550

[13] K. Sakata, Y. Masuda, Ferroelectric and antiferroelectric properties of $\left(\mathrm{Na}_{0.5} \mathrm{Bi}_{0.5}\right)-$ $\mathrm{TiO}_{3}-\mathrm{SrTiO}_{3}$ solid solution ceramics, Ferroelectrics 7 (1974) 347.

[14] V.A. Isupov, Ferroelectric $\mathrm{Na}_{0.5} \mathrm{Bi}_{0.5} \mathrm{TiO}_{3}$ and $\mathrm{K}_{0.5} \mathrm{Bi}_{0.5} \mathrm{TiO}_{3}$ perovskites and their solid solutions, Ferroelectrics 315 (2005) 123.

[15] W. Jo, J.E. Daniels, J.L. Jones, X. Tan, P.A. Thomas, D. Damjanovic, J. Rödel, Evolving morphotropic phase boundary in lead-free $\left(\mathrm{Bi}_{1 / 2} \mathrm{Na}_{1 / 2}\right) \mathrm{TiO}_{3}-\mathrm{BaTiO}_{3}$ piezoceramics, Journal of Applied Physics 109 (2011) 014110.

[16] D.L. West, D.A. Payne, Microstructure development in reactive-templated grain growth of $\mathrm{Bi}_{1 / 2} \mathrm{Na}_{1 / 2} \mathrm{TiO}_{3}$-based ceramics: template and formulation effects, Journal of the American Ceramic Society 86 (2003) 769.

[17] T. Kimura, T. Takahashi, T. Tani, Y. Saito, Preparation of crystallographically textured $\mathrm{Bi}_{0.5} \mathrm{Na}_{0.5} \mathrm{TiO}_{3}-\mathrm{BaTiO}_{3}$ ceramics by reactive-templated grain growth method, Ceramics International 30 (2004) 1161.

[18] X.X. Wang, K.W. Kwok, X.G. Tang, H.L.W. Chan, C.L. Choy, Electromechanical properties and dielectric behavior of $\left(\mathrm{Bi}_{1 / 2} \mathrm{Na}_{1 / 2}\right)(1-1.5 \mathrm{x}) \mathrm{Bi}_{\mathrm{x}} \mathrm{TiO}_{3}$ lead-free piezoelectric ceramics, Solid State Communications 129 (2004) 319.

[19] H.W. Cheng, X.J. Zhang, S.T. Zhang, Y. Feng, Y.F. Chen, Z.G. Liu, G.X. Cheng, Combinatorial studies of $(1-\mathrm{x}) \mathrm{Na}_{0.5} \mathrm{Bi}_{0.5} \mathrm{TiO}_{3}-\mathrm{xBaTiO}$ thin-film chips, Applied Physics Letters 85 (2004) 2319.

[20] H.D. Li, C.D. Feng, W.L. Yao, Some effects of different additives on dielectric and piezoelectric properties of $\left(\mathrm{Bi}_{1 / 2} \mathrm{Na}_{1 / 2}\right) \mathrm{TiO}_{3}-\mathrm{BaTiO}_{3}$ morphotropic-phaseboundary composition, Materials Letters 58 (2004) 1194. 
[21] X.X. Wang, S.W. Or, X.G. Tang, H.L.W. Chan, P.K. Choy, P.C.K. Liu, $\mathrm{TiO}_{2}{ }^{-}$ nonstoichiometry dependence on piezoelectric properties and depolarization temperature of $\left(\mathrm{Bi}_{0.5} \mathrm{Na}_{0.5}\right)_{0.94} \mathrm{Ba}_{0.06} \mathrm{TiO}_{3}$ lead-free ceramics, Solid State Communications 134 (2005) 659.

[22] J.S. Song, S.J. Jeong, I.S. Kim, D.S. Lee, E.C. Park, Piezoelectric and dielectric properties in grain oriented $\left(\mathrm{Bi}_{0.5} \mathrm{Na}_{0.5}\right) \mathrm{TiO}_{3}-\mathrm{BaTiO}_{3}$ ceramics, Ferroelectrics 338 (2006) 1419.

[23] W.S. Chang, L.C. Lim, P. Yang, H. Miao, C.S. Tu, Q. Chen, A.K. Soh, Tetragona micro/nanotwins in $0.91 \mathrm{~Pb}\left(\mathrm{Zn}_{1 / 3} \mathrm{Nb}_{2 / 3}\right) \mathrm{O}_{3}-0.09 \mathrm{PbTiO}_{3}$ revealed by reciproca space mapping, Applied Physics Letters 94 (2009) 202907.

[24] Y.U. Wang, Diffraction theory of nanotwin superlattices with low symmetry phase: application to rhombohedral nanotwins and monoclinic $\mathrm{M}_{\mathrm{A}}$ and $\mathrm{M}_{\mathrm{B}}$ phases, Physical Review B: Condensed Matter 76 (2007) 024108.
[25] C.S. Tu, S.H. Huang, C.S. Ku, H.Y. Lee, R.R. Chien, V.H. Schmidt, H. Luo, Phase coexistence and Mn-doping effect in lead-free ferroelectric $\left(\mathrm{Na}_{1 / 2} \mathrm{Bi}_{1 / 2}\right) \mathrm{TiO}_{3}$ crystals, Applied Physics Letters 96 (2010) 062903.

[26] D. Viehland, S.J. Jang, L.E. Cross, M. Wuttig, Deviation from Curie-Weiss behavior in relaxor ferroelectrics, Physical Review B: Condensed Matter 46 (1992) 8003.

[27] V.H. Schmidt, G.F. Tuthill, C.S. Tu, T.V. Schogoleva, S.C. Meschia, Conductivity across random barrier distribution as origin of large low-frequency dielectric peak in perovskite crystals and ceramics, Journal of Physics and Chemistry of Solids 57 (1996) 1493. 